Linköping Studies in Science and Technology. Dissertations.

No. 1636

\title{
Optimal Predictive Control of Wheel Loader Transmissions
}

Tomas Nilsson

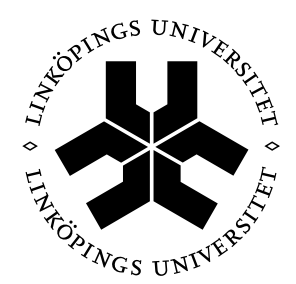

Linköpings universitet

INSTITUTE OF TECHNOLOGY

Department of Electrical Engineering

Linköpings universitet, SE-581 83 Linköping, Sweden

Linköping 2015 
Linköping Studies in Science and Technology. Dissertations. No. 1636

This is a Swedish Doctoral Dissertation.

A Doctor's degree comprises 240 ECTS credits (4 years of full-time postgraduate studies), of which at least 120 ECTS credits constitute a doctoral dissertation.

\section{Optimal Predictive Control of Wheel Loader Transmissions} ISBN 978-91-7519-171-3

ISSN 0345-7524

(c) 2015 Tomas Nilsson, unless otherwise noted. All rights reserved.

Tomas Nilsson

tomas.nilsson@liu.se

www.vehicular.isy.liu.se

Division of Vehicular Systems

Department of Electrical Engineering

Linköping University

SE-581 83 Linköping, Sweden

The cover illustrations show wheel loaders at work.

(C) 2014 Volvo Construction Equipment, Reproduced with the permission of Volvo Construction Equipment.

https://images.volvoce.com

Typeset with $\mathrm{AT}_{\mathrm{E}} \mathrm{X} 2 \varepsilon$

Printed by LiU-Tryck, Linköping, Sweden 2015 
To my wife Malin and my son Vilhelm 



\section{Abstract}

The transmissions of present heavy wheel loaders are in general based on torque converters. The characteristics of this component suits these machines, especially in that it enables thrust from zero vehicle speed without risk of stalling the engine, without active control. Unfortunately, the component also causes losses which might become large compared to the transmitted power. One approach for mitigating these losses is to switch to a continuously variable transmission. Changing to such a system greatly increases the possibility, and the need, for actively selecting the engine speed, and here a conflict emerges. A low engine speed is desired for high efficiency but a high speed is required for high power.

Heavy wheel loaders often operate according to a common repeating pattern known as the short loading cycle. This cycle is extremely transient, which makes the choice of engine operating point both important and difficult. At the same time, the repeating pattern in the operation enables a rough prediction of the future operation. One way to use the uncertain prediction is to use optimization techniques for selecting the best control actions. This requires a method for detecting the operational pattern and producing a prediction from this, to formulate a manageable optimization problem, and for solving this, and finally to actually control the machine according to the optimization results. This problem is treated in the four papers that are included in this dissertation.

The first paper describes a method for automatically detecting when the machine is operating according to any of several predefined patterns. The detector uses events and automata descriptions of the cycles, which makes the method simple yet powerful. In the evaluations over $90 \%$ of the actual cycles are detected and correctly identified. The detector also enables a quick analysis of large datasets. In several of the following papers this is used to condense measured data sequences into statistical cycles for the control optimization.

In the second paper dynamic programming and Pontryagin's maximum principle is applied to a simplified system consisting of a diesel engine and a generator. Methods are developed based on the maximum principle analysis, for finding the fuel optimal trajectories at output power steps, and the simplicity of the system enables a deeper analysis of these solutions. The methods are used to examine and visualize the mechanisms behind the solutions at power transients, and the models form the basis for the models in the following papers.

The third paper describes two different concepts for implementing dynamic programming based optimal control of a hydrostatic transmission. In this system one load component forms a stochastic state constraint, and the concepts present two different strategies for handling this constraint. The controller concepts are evaluated through simulations, in terms of implementability, robustness against uncertainties in the prediction and fuel savings.

The fourth paper describes the implementation and testing of a predictive controller, based on stochastic dynamic programming, for the engine and generator in a diesel electric powertrain. The controller is evaluated through both simulations and field tests, with several drivers, at a realistic work site, thus including all relevant disturbances and uncertainties. The evaluations indicate $\mathrm{a} \sim 5 \%$ fuel benefit of utilizing a cycle prediction in the controller. 


\section{Populärvetenskaplig sammanfattning}

Precis som för andra fordon finns det en vilja att sänka bränsleförbrukningen för hjullastare genom att hitta och minska de energiförluster som finns i systemet. Drivlinan i dagens tyngre maskiner är uppbyggd kring en momentomvandlare. Denna komponent gör att momenten i drivlinan anpassas till fordonets och motorns hastigheter, så att om maskinen t.ex. kör fast så ökar det drivande momentet på hjulen samtidigt som lasten på motorn inte ökar, helt utan någon aktiv styrning. Detta gör drivlinan självreglerande och mekaniskt robust, och gör även att maskinen kan ha hög drivande kraft från stillastående. Tyvärr ger momentomvandlaren även förluster, som i vissa lägen kan vara mycket stora i förhållande till den effekt som används för att förflytta maskinen. Andra möjliga lösningar för drivlinan i dessa maskiner är att använda el- eller hydraulmotorer för framdrivningen, och att använda en dieselmotor kopplad till en generator eller hydraulpump för att driva dessa. Transmissionen i en sådan diesel-elektrisk eller diesel-hydraulisk drivlina fungerar då som en steglös växellåda. Med en sådan uppstår möjligheten, och kravet på, att aktivt välja motorvarvtal, och här uppstår en konflikt. Lågt varvtal ger låg bränsleförbrukning och högt varvtal ger bra respons, men det tar tid att byta varvtal. En genomtänkt strategi behövs därför för att välja varvtal, speciellt vid snabba effektförändringar.

Tyngre hjullastare arbetar ofta enligt ett vanligt mönster, där den korta lastarcykeln upprepas gång på gång. I denna cykel kör maskinen fram och fyller sin skopa från en källa, backar, kör fram och tömmer skopan i en mottagare, backar tillbaka och sedan upprepas cykeln. Detta mönster är väldigt transient; hastigheten och effektbehovet är sällan konstant, vilket gör valet av motorarbetspunkt extra svårt. Samtidigt innebär regelbundenheten att det finns en generell kunskap om hur maskinen kommer att användas i den nära framtiden, kunskap som bör användas i motorstyrningen. Ett sätt att använda den osäkra förutsägelsen är att använda optimeringsteknik för att i varje tidpunkt hitta den bästa styrsignalen. För att göra detta krävs en metod för att hitta mönstren i hur maskinen används och skapa en prediktion från detta, att formulera optimeringsproblemet så att detta blir hanterbart, att lösa detsamma, och slutligen att faktiskt styra maskinen enligt resultaten från optimeringen. Detta probelm behandlas i denna avhandling, som i huvudsak är uppbyggd kring fyra artiklar.

Den första artikeln beskriver en detektor som automatiskt registrerar om maskinen arbetar enligt något av flera fördefinierade mönster. Denna gör det bland annat möjligt att snabbt analysera stora datamängder och kondensera dessa till statistiska mönster. Dessa kan, som i flera av de följande artiklarna, användas för att beräkna optimala styrlagar för varje mönster. Den andra artikeln undersöker de mekanismer som styr den bränsleoptimala lösningen för ett enklare system bestående av en dieselmotor kopplad till en generator, och visualiserar dessa. Den tredje artikeln beskriver och utvärderar två olika implementationer av optimal styrning av en hydrostatisk transmission, med avseende på implementerbarhet, robusthet mot prediktionsosäkerhet och bränslebesparing. Den fjärde artikeln beskriver optimal styrning av en diesel-elektrisk drivlina, med formuleringen av optimeringsproblemet, lösningen av detta, till implementation och tester utförda i maskin med flera förare på en realistisk arbetsplats. 


\section{Acknowledgment}

Even though there is only one author of this dissertation, there are many persons that deserve acknowledgment for contributing, in many different ways, to the work presented, for the rewarding discussions which sometimes even were on the topics of this dissertation, and for the enjoyable atmosphere at the group.

I would like to start by thanking my colleagues at the Division of Vehicular Systems at Linköping University. First of all our professor and my co-supervisor Lars Nielsen for giving me the opportunity to work at his group with this rewarding project, and my first supervisor Jan Åslund for his supervision and assistance in my work on the project presented in this dissertation. I would like to acknowledge all the work my coauthors at the group; Peter Nyberg, Christofer Sundström, Erik Frisk, Mattias Krysander and Jan Åslund, have put into the papers which makes up the dissertation. Further, I would like to thank all my colleagues for the pleasant atmosphere at the group. I have had very interesting discussions on the different topics of our research and related to our undergraduate teaching, I have enjoyed the interesting fika-room discussions, and I will always carry with me the experiences from our conference trips.

I would like to thank all those at Volvo Construction Equipment who have contributed to or participated in the work presented here. First of all I would like to thank my supervisor Anders Fröberg for his invaluable support, from proposing research directions to providing the test vehicle for the final paper. I would like to thank Rickard Mäki and Jonas Larsson for their support of the projects that resulted in my papers. I would also like to thank all others who have contributed with material or their time, and especially mention my previous supervisor Gianantonio Bortolin, and Bobbie Frank and Mikael Skantz. This dissertation would not have been possible without your assistance.

Last but not least, I would like to thank my wife Malin for her endless support and for, together with my son Vilhelm, always reminding me that there is much more to life than writing a dissertation. 


\section{Contents}

$\begin{array}{ll}\text { Introduction } & 1\end{array}$

1 Introduction $\quad 3$

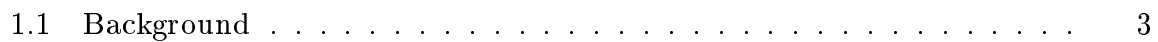

1.2 Outline and Contributions . . . . . . . . . . . . 6

2 Optimal predictive control $\quad 9$

2.1 Overview and definition . . . . . . . . . . . . . . 9

2.2 Prediction . . . . . . . . . . . . . . . . . 11

2.3 Optimization .................................. 12

2.4 Optimal predictive control for wheel loaders . . . . . . . . . . 15

3 Wheel loader operation $\quad \mathbf{1 7}$

3.1 Overview and the Short Loading Cycle . . . . . . . . . . . . . . 17

3.2 Repetition detection .................... 19

$\begin{array}{ll}\text { References } & 23\end{array}$

$\begin{array}{ll}\text { Papers } & 29\end{array}$

1 Robust driving pattern detection and identification with a wheel $\begin{array}{ll}\text { loader application } & 31\end{array}$

1 Introduction . . . . . . . . . . . . . . . . . 32

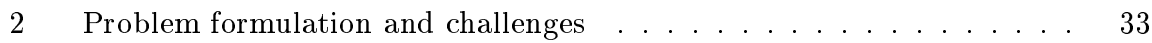

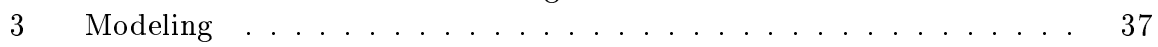

4 Method ......................... 40

$5 \quad$ Evaluation . . . . . . . . . . . . . . . . 44 


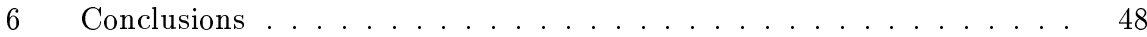

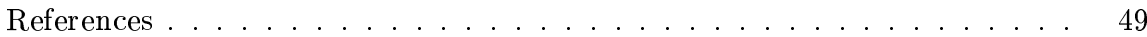

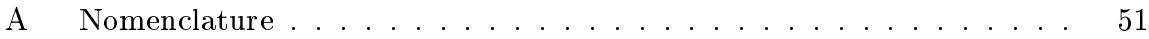

2 Minimizing Fuel Use During Power Transients for Naturally Aspirated and Turbo Charged Diesel Engines 53

1 Introduction . . . . . . . . . . . . . . . . . 54

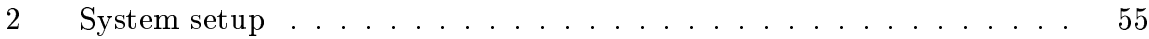

3 Problem statement . . . . . . . . . . . . . . . . 58

4 Optimization Methods . . . . . . . . . . . . . . . 59

$5 \quad$ Engine map and static optimal solution . . . . . . . . . . . 62

6 DP derived optimal trajectories . . . . . . . . . . . . . . 63

$7 \quad$ PMP trajectory derivation . . . . . . . . . . . . . 66

8 Suboptimal method development . . . . . . . . . . . . . . . 74

9 Discussions and comments . . . . . . . . . . . . . . 76

References . . . . . . . . . . . . . . . . . . 78

3 Development of look-ahead controller concepts for a wheel loader $\begin{array}{lr}\text { application } & 81\end{array}$

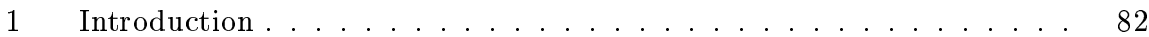

2 Models ........................... 83

3 Methods ........................... 90

4 Evaluation . . . . . . . . . . . . . . . 100

5 Summary and Conclusions . . . . . . . . . . . . . . . . 112

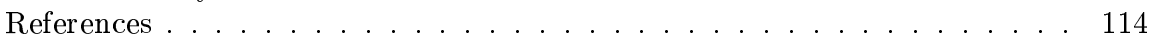

4 Predictive control of a diesel electric wheel loader powertrain $\quad \mathbf{1 1 7}$

1 Introduction . . . . . . . . . . . . . . . . . . . . . 118

2 System and concept overview . . . . . . . . . . . . . . . . . 119

3 Controller descriptions . . . . . . . . . . . . . . . . . . 126

4 Measurements . . . . . . . . . . . . . . . . . . . . 130

$5 \quad$ Results . . . . . . . . . . . . . . . . . . . . 132

6 Discussion and Conclusions . . . . . . . . . . . . . . . . 139

References . . . . . . . . . . . . . . . . . 140 



\section{Introduction}





\section{Introduction}

\subsection{Background}

The wheel loader is a type of engineering vehicle mainly designed for short distance handling of bulk material, but also used in a wide range of other applications. An example of the vehicle type is shown in Figure 1.1. As an off-road engineering vehicle it is seldom used for longer transports, but more often in high force and/or high precision operations at relatively low vehicle speeds. For this reason, the transmission of the vehicle is designed for being mechanically robust and to have smooth and predictable low speed/high torque characteristics. In particular, the transmission has to be able to provide high wheel torque from standstill up to some speed without gear change jerks, and also have characteristics that prevents the engine from stalling if the driving resistance increases suddenly, as if the bucket hits an obstacle during a bucket filling. The most common solution for heavy loaders is to base the transmission on a torque converter [51, 52, 53, 54, 55, 56]. Basic descriptions and models of torque converters can be found in [27] and in [25], and in papers where the devices are used, such as in [37], [62] and [69]. The characteristics of a torque converter generally follows, and is usually presented as in, the example in Figure 1.2. In a hydrodynamic torque converter the propelling connection drives a flow of oil, and the flowing oil drives the propelled connection. The propelling connection is therefore denoted the pump side and the propelled connection is denoted the turbine side. Figure 1.2 shows the pump torque $T_{P}$, measured at a specific pump speed which in this case is $1000 \mathrm{rpm}$, and normalized with the torque at $\omega_{T}=0$. It also shows the relation between pump torque and turbine torque $T_{T}$ and the transmission efficiency $\eta$, which is the speed relation multiplied with the torque relation. All of these are drawn as functions of the output to input speed ratio 
$\phi=\omega_{T} / \omega_{P}$ or the slip $s=1-\phi$. The pump torque is, for a fixed pump speed, relatively constant up to some speed ratio where it starts to drop and is close to zero at $\phi=1$. This means that if the vehicle drives at high slip, a disturbance in vehicle speed or wheel torque will not increase the load on the engine much. Thus the engine is prevented from stalling if the vehicle experiences an increase in driving resistance, and at the same time such a disturbance will cause the propelling torque to increase according the $T_{T} / T_{P}$ relation. It is important to note that the torque converter also allows the vehicle speed to go to zero without any active action, such as the releasing of clutches. For wheel loaders these properties are particularly important, especially during the bucket filling where the vehicle drives at a low speed and experiences high and unpredictable forces from the bucket to ground contact, and this is one reason torque converters are so common in heavy wheel loaders. The drawback is that the transmission of torque requires some slip, and there is considerable power lost due to this slip. In many other applications the high losses can be mitigated by having a lockup function in the torque converter, as indicated e.g. in the models in [25], in which the input and output shafts are locked together by a clutch thus negating the slip and the related losses. This can however only be done if relatively constant vehicle speed is expected and the available gears places the engine speed in its allowed speed envelope. For wheel loaders this would only be possible in more static operations at higher speeds such as in transports, and not in the more common highly transient and low speed loading operations.

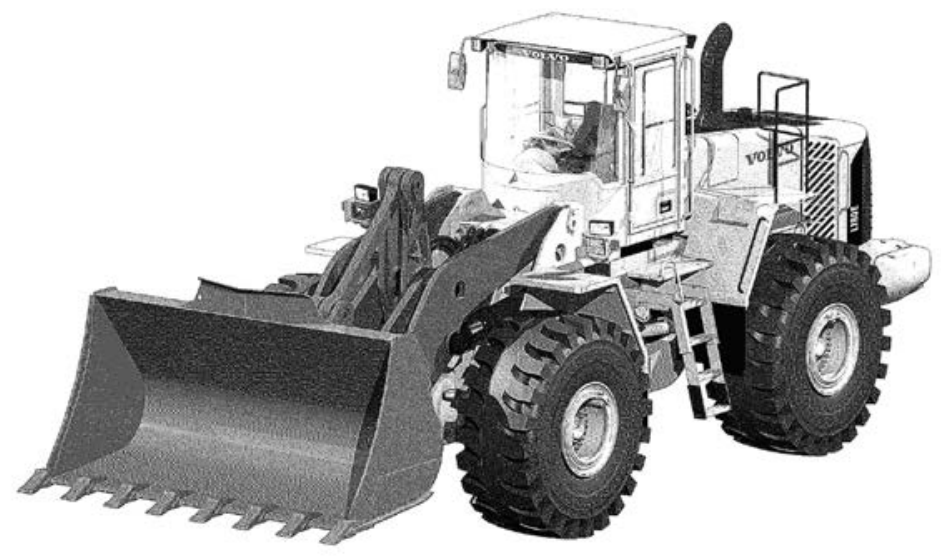

Figure 1.1: An example of a wheel loader, from [18].

Electric and hydraulic motors have very different characteristics as compared to internal combustion engines, especially in that these can produce torque from standstill. The electric or hydraulic power required to run the motor can come from a generator or hydraulic pump, which could be propelled by an internal combustion engine. For such a system the electric motor and generator, or hydraulic motor and pump, becomes an infinitely variable transmission (IVT), corresponding to a gearbox which has not only infinitely many gears, but also infinite gear ratios [48]. Transmissions of this type has for a long time been 


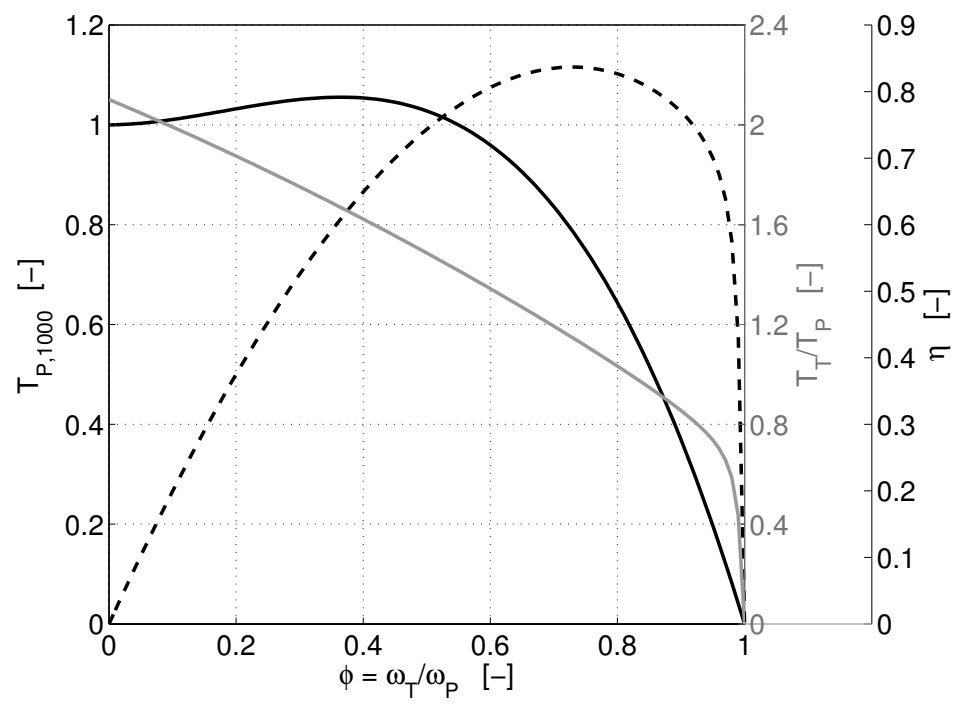

Figure 1.2: An illustration of torque converter characteristics. The black line shows the pump, or input, torque $T_{P, 1000}$, the gray line shows the output to input torque ratio $T_{T} / T_{P}$ and the dashed line shows the efficiency $\eta=\omega_{T} T_{T} / \omega_{P} T_{P}$.

used in some special applications, such as diesel-electric locomotives [28, 31] and hydraulic drives in excavators [97], and have more recently attracted some attention as transmissions in regular vehicles [13, 45, 46, 91]. A related transmission type is the continuously variable transmission (CVT), which corresponds to a gearbox with an infinite number of gears but with a limited span of gear ratios. These drives are more commonly mechanical solutions, such as the belt type CVTs in [90]. These types of transmissions can also be expanded with a significant energy storage, such as a battery [16], supercapacitor [17], pressure vessel [30] or flywheel [85], to form a series hybrid powertrain. Regardless of the type of transmission, the infinite number of gear ratios greatly increases the freedom in actively selecting the engine speed. In transients, when there is a non-zero engine speed derivative, the engine speed controller also has to take into account the power flow to or from the engine inertia. The problem of selecting the engine speed for this type of system in transient conditions has been studied e.g. in [44] and [76], and more recently in [67] and [86]. Since the engine speed is free, the main characteristic of the load is the power required in the electric/hydraulic/other connection. For static, or quasi static, load power the engine speed can be placed at the corresponding static fuel optimal operating point. These operating points, as a function of output power, are in general located near the maximum torque line of the engine, which means that there is little margin for handling sudden increases in the demanded output power. If the engine speed is low and there is a sudden increase in the desired output power, the engine will have to speed up before supplying this power, which causes a delay. In case there is a turbo this device will also have to speed 
up, a process that can have a time constant of several tenths of a second [87]. Common delays of this magnitude would not be acceptable in such transient operation as that of wheel loaders. Another strategy that would not cause such delays could be to always maintain high engine and turbo speeds, though this would reduce the average efficiency of the engine. So, the engine speed should be low when the requested power is low and high when the power is high, but due to the time constants in the system this would require a load prediction.

In the most common operation of wheel loaders, which is short distance loading, the vehicle operation consists of repeating a distinct cycle known as the short loading cycle, as described in detail in [19]. The distinct and repetitive operation according to this cycle means that at the beginning of a cycle, the general appearance of the rest of the cycle can be predicted. In case the torque converter has been replaced with a CVT type transmission, the engine speed is actively controlled, and in this controller the information obtained through the cycle prediction should be utilized. There has been a substantial amount of work done on optimal control against predicted future operating conditions, in many fields both theoretical and applied. In most of the work with vehicle applications the prediction has however been deterministic. Some, like [76], of these has focused on pure dynamic optimization, without considering online implementations. Others, such as [29] and [36], have considered, or even implemented, online controllers but still assumed a deterministic prediction in their optimization. For the wheel loader however, even though the general appearance of the cycle can be predicted, the details of each individual cycle cannot, and a predictive controller would have to rely on a partly stochastic prediction. There are some vehicle related papers in which stochastic predictions are used; [35], [26] and [39] are just some. The controllers presented are in general focused on systems with dynamics that are considerably slower than the engine speed dynamics though, such as the battery state of charge in hybrid electric vehicles. The papers included in this dissertation describe work related to the development and implementation of a predictive controller for the engine dynamics in a CVT (or IVT) based wheel loader powertrain.

\subsection{Outline and Contributions}

This dissertation describes the development, implementation and testing of different algorithms necessary for utilizing the repetitiveness in the operation for optimal predictive control of a continuously variable wheel loader transmission. The dissertation starts with an introduction in three chapters, where the present chapter, Chapter 1, gives a background to the problem addressed and a summary of the papers included. Chapter 2 describes and defines the concept of optimal predictive control and its components, and Chapter 3 describes the particular properties of wheel loader operation that is an enabler for the prediction. This introduction is followed by the main part of the dissertation, which consists of the four papers [73], [70], [69] and [72]. In the rest of this section these papers are summarized, and the addressed problems are motivated in the context of the theme of this dissertation. 


\section{Paper 1: Robust driving pattern detection and identification with a wheel loader application, [73].}

The first problem was to find a method for obtaining a prediction of future operation. Two general approaches was identified; to base the prediction on repetition detection or on pattern detection. While both of the approaches were promising from a prediction point of view, the second was considered more practical practical for optimization purposes. The repetition detection is described further in Section 3.2. More work was put into the pattern detection track, and the result is presented the appended paper.

Paper 1 presents a framework for off- and online automatic detection and identification of operation according to a set of predefined wheel loader operational cycles. In this detector the cycles are constructed from a small set of discrete events, such as a change of driving direction or a bucket emptying, forming a unique sequence for each type of cycle. The paper is focused on the short loading cycle, and the detector is evaluated offline and online in handling of different materials by different drivers. The evaluation shows positive results of this simple but capable detector, with over $90 \%$ of all cycles detected, even in difficult operation such as handling of shot rock.

The detector described is highly useful for quickly analyzing and condensing large amounts of recorded data, by extracting the cycles and relevant information for these, so that this information can be summarized into a manageable cycle description suited for the optimization. In this role the cycle detector has been used in all the papers [65], [66], [69], [68], [71] and [72]. The substantial benefit of having the cycle detector when analyzing large sets of data is the main contribution of this paper.

\section{Paper 2: Minimizing Fuel Use During Power Transients for Naturally Aspirated and Turbo Charged Diesel Engines, [70].}

The next problem was to construct system models and selecting an optimization method suited to the problem at hand. The initial study focused on using simple models and trying to find underlying mechanisms in the optimal trajectories that could be utilized for simplifying the larger optimization problem.

Paper 2 is a technical report based on a section of the licentiate thesis [63], which in turn is an extension of the papers [64] and [67]. The paper analyzes the problem of finding the optimal operating point trajectories for a naturally aspirated or turbo charged engine connected to a generator, during output power transients. The problem is a simplified version of optimal control of the engine and generator in a diesel electric transmission, especially in that the power trajectory is deterministic. Instead of focusing on application of the solutions, the optimal engine operating point trajectories are studied in depth using both dynamic programming and Pontryagin's maximum principle.

The contribution of this paper is a deeper understanding of the mechanisms behind the fuel optimal solutions for power transients, and a pedagogical example of how Pontryagin's maximum principle can be used for finding the optimal trajectories for simple problems. The models introduced in this paper are used in the papers [65], [66], [69], [68], [71] and [72]. 


\section{Paper 3: Development of look-ahead controller concepts for a wheel loader application, [69].}

With the general prediction and optimization methods or concepts selected, the final problem was to implement and adapt these for use as an online controller in a wheel loader. In this implementation study a specific transmission was selected, a device presented in the patent [50]. The main problem in the implementation was how to handle the uncertainties in the prediction.

Paper 3 describes two dynamic programming based controller concepts for a wheel loader with a three mode hydrostatic continuously variable transmission. The two concepts present very different strategies for handling prediction uncertainties, especially in the requested hydraulic flow, since this flow introduces a stochastic state constraint. The first controller includes uncertainties in the load description, and is based on the papers [65] and [66]. The second concept uses the possibility of reducing the vehicle speed, and is based on the paper [68], supplemented with a small time delay in the hydraulics. The paper [69] focuses on the reformulations required for online implementation of the concepts, followed by an evaluation of these implementations.

The main contribution is the study into how the stochastic state constraint introduced by the hydraulic flow can be handled in the optimization. The paper also forms a feasibility study for predictive controllers for the transmission concept described, and in case a similarly equipped machine becomes available, the proposed strategies could form the basis of a predictive engine speed controller.

\section{Paper 4: Predictive control of a diesel electric wheel loader power- train, [72].}

The final problem of implementing the selected prediction and optimization methods was approached again, but with a different transmission layout, based on the machine presented in [92]. The layout enabled a simpler load description, and since a machine was available for field tests, the controller concept could be implemented and tested.

Paper 4 treats the implementation and testing of a controller for the engine operation in a diesel electric wheel loader transmission. The main controller is based on stochastic dynamic programming, with a load probability distribution that depends on the distance driven. This controller is evaluated in both simulations and field tests against two simpler reference controllers. The optimized control schemes were first evaluated in [71], but only through simulations that did not include the influence of model errors, an uncertain environment and unpredictable driver feedback. In the included paper, the controllers are also field tested in a realistic operation scenario with three different drivers, thus including all relevant disturbances and uncertainties.

The main contribution of the paper [72] is an evaluation, which includes field tests, of the possible benefit of utilizing a cycle prediction in a continuously variable wheel loader transmission controller. Both simulations and field tests indicate a $5 \%$ fuel benefit of utilizing the cycle prediction in the engine controller. The paper is also a logical closing of the dissertation in that all the main parts developed are collected and tested together in a realistic implementation. 


\section{Optimal predictive control}

\subsection{Overview and definition}

This dissertation treats optimal predictive control (OPC) of a continuously variable transmission in a wheel loader. Section 2.1 gives a broad definition of the concept of OPC and relates this to similar concepts such as model predictive control. Sections 2.2 and 2.3 describes the two components 'prediction' and 'optimization' required for this type of control, with brief introductions to the concepts, and some background and examples. Section 2.4 relates the described prediction and optimization methods to wheel loader operation, and motivates the choices that are made in this dissertation.

Optimal predictive control is here defined as a control method in which the control action at each moment is decided through optimization with respect to a prediction of future disturbance signals. Denoting the states of the system $x$, the control signals $u$ and the disturbance signals $w$, the problem can be summarized according to Equation (2.1). It is assumed that there exists a prediction of the signals in $w$, although the prediction might include uncertainties, might have a limited time horizon $t_{\vartheta}$ and might not become available until the moment $t_{k}$ when the control action $u\left(t_{k}\right)$ should be decided upon.

$$
\begin{aligned}
\lim _{T \rightarrow \infty} \min _{u \in U} \frac{1}{T} \int_{t_{k}}^{T} G(x(t), u(t), w(t, x, u)) \mathrm{d} t \\
\frac{d x}{d t}=F(x(t), u(t), w(t, x, u)) \\
0=C(x(t), u(t), w(t, x, u)) \\
x_{0}=x(0)
\end{aligned}
$$


For practical reasons, the cost function (2.1a) is in general replaced with the truncated cost function (2.2), and the truncation is in general made inside the prediction horizon, so that $N \leq \vartheta$.

$$
\min _{u \in U}\left\{J_{N}\left(x\left(t_{N}\right)\right)+\int_{t_{k}}^{t_{N}} G(x(t), u(t), w(t, x, u)) \mathrm{d} t\right\}
$$

In the general control process, at each moment $t_{k}$, a prediction of $w\left(t_{k}, \ldots, t_{\vartheta}\right)$ is obtained and an optimization is performed based on this prediction to find the minimizing $u\left(t_{k}, \ldots, t_{N}\right)$. The first control action $u\left(t_{k}\right)$ is applied and the process is repeated at the next time step. This description is very similar to model predictive control (MPC), as described in detail in [14] and [22], in that the MPC is also based on a system model, which is used for making a prediction of the system behavior and finding the best control action. In its most classical form the MPC problem is formulated according to equation (2.3). In this formulation $y$ are measurable outputs, $r$ are references or targets for the outputs, $u$ are control signals, $\lambda$ are weighting factors, $x$ are states, $A, B, C$ and $D$ are matrices and $Z_{u}$ and $Z_{x}$ are control and state constraints.

$$
\begin{aligned}
\min _{u} & =\sum_{j=1}^{N}\left\{\left(y_{j}-r_{j}\right)^{2}+\lambda_{j} u_{j-1}^{2}\right\} \\
x_{j+1} & =A_{j} x_{j}+B_{j} u_{j} \\
y_{j} & =C_{j} x_{j}+D_{j} u_{j} \\
Z_{u, j, l} & \leq u_{j} \leq Z_{u, j, h}, \quad Z_{x, j, l} \leq x_{j} \leq Z_{x, j, h}
\end{aligned}
$$

This control approach is an alternative to classical PID-type controllers, which is useful if the controlled system has many inputs, outputs or states, or if there are significant constraints. Further, the method can also utilize a prediction of reference state changes. There are also several mature software packages for MPC, such as [7]. Still, the classical formulation in Equation (2.3) is highly restrictive in that it requires a linear model, a cost that is a quadratic function of control action and deviation from know references, and is unable to utilize a prediction of future disturbances. There are however several extensions and modifications of this classical MPC formulation intended for removing these restrictions. Some of the more known extensions are generalized predictive control (GPC), robust MPC (RMPC) and nonlinear MPC (NMPC), each of which mainly address one specific deficiency in the classical MPC formulation. For these specific examples, GPC introduces a prediction of measurable disturbances, RMPC considers uncertainties in the models used and NMPC introduces nonlinearities in the models [14]. There are many more advanced formulations proposed or used, see for example [79], although there is less consistency in the notation for these formulations. In this work it was decided not to use MPC related notations even though the OPC problem could be formulated in the MPC framework. This was partly because there is no well established notation within the field of MPC for the type of problem studied here, but mostly because the MPC notation is associated with the classical formulation and control towards known, and often constant, reference values. 
In the problem studied here, it is assumed that there exists a prediction of future operating conditions, that this prediction contains significant uncertainties, and that the prediction might change over time. It is also assumed that there exists a model of the controlled system. At each instant the available prediction and the system model should be used for solving the, possibly truncated, problem (2.1), so that the optimal control action can be applied. The following two sections describe some different methods for obtaining a prediction and for calculating the optimal control action.

\subsection{Prediction}

It is assumed that there are some external signals $w(t)$, here denoted disturbance signals, affecting the system and that there exist a prediction of these disturbance signals. The prediction is an enabler for optimal predictive control, and its properties are crucial for how the controller could be implemented. The main properties of the prediction are the prediction horizon $t_{\vartheta}$ and the level of uncertainty in the prediction, although there are other important properties such as the number of components in $w$. The prediction horizon affects the choice of optimization horizon $t_{N}$ and the required complexity of the residual cost function $J_{N}\left(t_{N}\right)$, which is the cost associated to each state at the end of the optimization horizon. The uncertainty in the prediction affects which optimization methods that are suited to the problem. There are several papers in the field of vehicular control suggesting a wide range of different methods for obtaining a disturbance prediction, with specified or unspecified purposes. In the following a few different types of predictions, their properties and some examples, are listed. This list does by no means purport to be complete, but is only a selection of some interesting and illustrative examples.

A first category of predictions are the deterministic route based predictions, in which the external disturbances are known functions of some of the states of the system. One example of this type is the topography information from road maps used in the optimal predictive controller described in [29]. For this type of prediction, since the whole $w(x)$ map is known beforehand, there is in practice no prediction horizon that limits the optimization horizon and the optimal control actions as functions of the state could in theory be precalculated. In practice, precalculation of the optimal control actions as a function of the states is in general not possible though, primarily due to the size of the maps in the route database.

Another type of predictions are the observations based predictions, in which there are some type of sensors which are able to 'scan ahead' of the controlled system. Data, such as topography or the traffic situation, can be communicated from other vehicles; this is a novel field of research known as cooperative driving, where [40], [77] and [5] are just a few examples. Using forward looking radars for adaptive cruise control and collision avoidance or mitigation is becoming common in new cars, and has been thoroughly investigated [11, 98], and in later years there has been research and implementations where the radars are supplemented with, or replaced by, camera based systems [4, 8, 21, 89]. Common for this type of predictions are that the whole disturbance function is not known 
beforehand, but there is a prediction horizon that gives an upper limit for the optimization horizon and the control actions can therefore not be optimized beforehand. These predictions in many cases contain some uncertainties that usually grow larger the further away the observations are, making the prediction horizon a somewhat murky concept.

A third type are predictions based on pattern recognition, in which the patterns can be predefined or evolving. In the predefined case there is a set of patterns and the predictor uses sensor data to select that which reflects the current operation and base the prediction on that pattern. This type includes identification or classification of driving type [34, 41] or situation [58, 74]. In the evolving pattern case the predictor tries to find recurring structures in the data, and base the prediction on these structures. This type is less common since the detector could produce unexpected results and because just loose enough assumptions has to be made of what form of recurring structures the detector should look for. In both of these types the predictions can be expected to contain relatively large uncertainties, which has to be considered in the optimization. Just as with the upstream observations, it can be expected that the uncertainties grow with the prediction horizon, especially in the evolving pattern prediction.

A fourth type of predictions are the stochastic Markov process disturbance models [24, 80], in which the disturbance signals are described by probability distributions, where the probability $p$ of a specific disturbance at the instant $t_{k}$ depends only on the state at the same instant, as described by $p\left(w_{k} \mid x\left(t_{k}\right)\right)$. The disturbance at the previous instant $w_{k-1}$ is however often included as a state. Since the process is memoryless, and the probability distributions are time invariant, a prediction of more than one step into the future becomes meaningless. Since the load descriptions are time invariant, the type should be considered semi-predictive; the models can describe and predict the evolution of a transient episode, but not the occurrence of a transient after stationary operation. Despite the simplicity of the models, from a prediction point of view, these have found use in several applications such as power split control in hybrid electric vehicles [42, 59, 81], route prediction [38, 83] and risk assessment $[32,82,95]$. Just as in the case of map- or database based predictions, since the whole $w(x)$ map is known beforehand, the optimal control actions as functions of the state can be precalculated. This approach is used in most implementations of stochastic dynamic programming, such as in [35], [57] and [39].

\subsection{Optimization}

Assuming that a prediction of some sort is available, the optimal predictive controller would at each stage select and apply the optimal control action. This implies that an optimization has been performed, either beforehand for all relevant state and load combinations, or as part of the selection of a control action at each stage. Both of these strategies have benefits and challenges. Performing the optimization beforehand requires first of all that the complete disturbance signal prediction is available before the process is started. This can be the case if the disturbances are either a limited number of deterministically known trajectories or can be formulated as uncontrollable states with stochastic tran- 
sitions, such as Markov chains. Still, even if this holds, the number of state and load combinations that would require a precalculated control action might be unmanageable. Performing the optimization online on the other hand requires that the optimization is quick compared to the time constants of the controlled system, or the optimal control action will no longer be optimal when it has been calculated. Just as in the offline optimization, the load description highly affects the calculatory effort. A deterministic prediction would only require a single trajectory to be optimized, while a stochastic prediction would require a more complex load alternative handling or load description for managing the branching tree of possible load trajectories. Both the off- and online strategies have been implemented in different forms, with different load descriptions and optimizers. The rest of this section gives brief descriptions of the three main classes of optimization algorithms, and relates these to the deterministic or stochastic, offline or online, optimization problem in optimal predictive control. The three classes are the dynamic programming or Hamilton-Jacobi-Bellman approach, the indirect methods, and the direct methods.

\section{Dynamic Programming}

Dynamic programming (DP) is a structured method for making a complete search of the entire discretized state and control space. The recursion, as described in [6] and [9], used can be formulated according to Equation (2.4).

$$
J_{k}\left(x_{k}\right)=\min _{u \in U}\left\{g\left(x_{k}, u_{k}, w_{k}\right)+J_{k+1}\left(x_{k+1}\left(x_{k}, u_{k}, w_{k}\right)\right)\right\}
$$

Since a complete search is made, this method guarantees global optimality. Furthermore, since the method is based on testing and not an iterative trajectory improvement, no derivatives are required. These properties together means that the method is not sensitive to non-convex or 'ugly' models containing switches, discontinuities, stochastic components, mixed discrete and continuous states and controls etc., in the same way as the indirect and direct methods are. The complete search however means that simulations has to be performed for all allowed controls from all allowed states for all possible disturbance signals, at all time steps, along with interpolations or other means required in the connecting of all the sub-trajectories. This ensures a high computational load, even for well posed problems, that grows exponentially with the number of states and controls. The method cannot manage problems with a combined number of more than about ten states plus control signals, and often problems with a far lower dimension become unmanageable. The method therefore in general suits problems where the calculation time is not critical, such as if the optimization can be done beforehand, with a low dimension and where there exist stochastic, nonconvex or nondifferentiable components. In [29] DP is used for control of vehicle speed and gear selection in a long haulage truck. The optimization is performed online with GPS data as input, and the method might be motivated by the discrete gears. There is a range of papers, such as [35], [57] and [39] that uses stochastic DP in vehicular controllers. In these cases the load is described by Markov models, and these stochastic predictions motivate the use of DP. 


\section{Indirect Methods}

The indirect methods are based on Pontryagin's minimum principle (PMP) [78]. The optimality conditions are formulated using the Hamiltonian (2.5).

$$
H=G(x(t), u(t), w(t))+\lambda(t) F(x(t), u(t), w(t))
$$

PMP then states that the minimizing state and control trajectories also minimizes this Hamiltonian. By differentiating the Hamiltonian with respect to the states and controls, a set of conditions necessary for optimality is obtained. The main conditions are (2.6), and the minimization problem is thus rephrased as a two point boundary value problem. The indirect methods are methods for solving this boundary value problem $[10,94]$.

$$
\begin{aligned}
\frac{\partial H}{\partial x} & =-\frac{d \lambda}{d t}=-\dot{\lambda} \\
\frac{\partial H}{\partial u} & =0 \\
\frac{\partial J_{N}}{\partial x} & =\lambda\left(t_{N}\right)
\end{aligned}
$$

The set of optimality conditions can be regarded as a generalization of the zero derivative condition in static one dimensional minimization. Just as in that simple case however, the conditions are only necessary but not sufficient conditions for optimality, unless the problem is convex, and if there are equality or inequality constraints the basic derivative conditions must be expanded with other terms. These other terms lead to state dependent switches and the system must therefore be continuously checked during the simulations to find any possible active constraint. Further, the extended system $\tilde{f}=[\dot{x}, \dot{\lambda}]$ forms a Hamiltonian system which means that, according to Liouville's theorem [43], the volume in the phase space of $[x, \lambda]$ is preserved $[15,61]$. This means that unless all states are close to the instability border, the problem will become unstable, which complicates the solving of the two point boundary value problem. Last but not least, if there are stochastic components in the system and the cost in the objective function is written as an expected value, the optimality conditions might not be well defined. The primary benefit of the indirect approach is that the formulation of the optimality conditions might reveal underlying structures in the solution to the optimization problem. In some very special problems the conditions might even lead to an analytical solution. One of the most important examples in the vehicular control area is probably the ECMS approach for controlling the power split in hybrid electric vehicles, as described in [75] and [84]. Other problems suited for indirect methods are marginally stable systems with few state constraints, such as space flight trajectory planning [49]. The indirect methods are otherwise in general suited for the same types of problems as the direct methods, and in later years the direct methods has taken over as being the most popular. 


\section{Direct Methods}

In the direct methods the original problem is discretized and the finite discrete problem is directly solved as a nonlinear optimization problem. In contrast to the indirect methods, there is no formulation of optimality conditions but an iterative search, using cost related derivatives, is performed for finding trajectories with increasingly low value of the cost function $(2.2)$ [10,94]. One drawback compared to the indirect methods is that the direct cannot give an explicit solution, regardless of the problem. The direct methods also require that the cost function, the state dynamics equations and the constraints can be differentiated, at least once, at least with respect to the controls, which means that the methods are not suited for 'ugly' models, with switches, discrete states, etc. Nor can the methods, just as with the indirect methods, guarantee global optimality or easily handle stochastic models. There are however several benefits with using direct methods, as compared to the indirect methods. The simulation of the system is simpler and more stable since the constraints are not formulated as switching conditions and a stable system is not made unstable by co-state dynamics. Since there is no need for formulating co-state dynamics or similar, setting up the problem is simpler than in the indirect methods. The effective solving of problems with these methods instead relies heavily on the effective calculation and handling of derivatives [93], for which there exist many mature software packages such as [3]. The increased simplicity, in general along with faster and more stable convergence, are reasons why the direct methods have become more popular than the indirect lately.

\subsection{Optimal predictive control for wheel loaders}

The characteristics of wheel loader operation opens up some different possibilities for prediction, related to the prediction types mentioned in Section 2.2. The nature of the operation, being off-road in a complex environment and with a human driver, does not provide for using route maps or similar for obtaining a prediction suited for optimization. Sensors such as cameras, radars or lidars can be added to the machine, as has been done as part of work focused on autonomous wheel loaders, e.g. in [2], [12], [23] and [47], to provide a close range awareness and prediction. The information obtained from such sensors would be of high reliability, but with a highly limited prediction horizon and only including information about the environment and not the intentions of the driver. The residual cost function $J_{N}(x)$ would be important, due to the relatively short prediction horizon as compared to the time constants of the turbo charged engine, but difficult to construct. Although this sensor based prediction possibility could be beneficial for component control, the available prediction horizon does not suit the intended application, while the uncertainties in the necessary time frame complicates the implementation of an optimizer.

As mentioned in Section 1.1, and described in greater detail in Section 3.1, the most common wheel loader operation consists of repeating a distinct cycle. This repetitive and pattern bound operation provides for some other means for obtaining a prediction. Two main approaches can be identified, where the 
choice of approach has a major impact on the requirements on the optimization method used, and so that this largely decides which approach that can be used. The first approach is to utilize the repetitiveness of the operation, and in the predictor try to detect if there is a repeating pattern in the operation, and build the prediction on an assumption of the detected pattern continuing into the future. Since such a detector would try to find repetition, it could be able to make predictions in a wide range of operations, with relatively little data predefined, making the detector highly versatile. While the detector would often be able to provide a prediction, this prediction would only become available to the optimizer when repetition is detected, and it would contain significant uncertainties. The optimizer would therefore need to run online and be able to handle stochastic predictions. Despite the versatility of this prediction type, and because of the difficulty of setting up and solving the resulting optimization problem, it was decided that this approach would not be the focus of the work presented in this dissertation. The implementation of a simple repetition based predictor for wheel loader operation is however described in Section 3.2. The second approach is to utilize the pattern bound operation, and in the predictor try to detect if the wheel loader is operating according to any of a set of predefined patterns, and build the prediction on an assumption of the detected pattern continuing into the future. This type of detection and prediction relies on the assumption that there is a limited number of patterns, or cycles, which the machine usually operate according to, and that these are known beforehand. If this assumption holds true, and the patterns are specific enough for an optimization, it is not necessary to perform the optimization online but it can be performed beforehand. For wheel loaders there exist a few common operation types, such as the short loading cycle described in Section 3.1. While this very broad operation description is common, it is in itself not detailed enough for optimization. On the other hand, it is common for this type of machine to operate at the same site, in the same environment, with the same tasks over longer times. In such a situation, the prediction and corresponding optimized controller can be based on the details of the operation performed over the previous hours or days, and the online controller can use a pattern detector for selecting the proper optimized control strategy. The predicted operational patterns would contain significant uncertainties but these would also be available to the optimizer early, and the time available for controller optimization would be in the order of hours. Because of the significant uncertainties in this type of prediction and the availability of time for calculation, it was decided that the dynamic programming methods were the most appropriate tools for the controller optimization. This last concept of prediction according to predefined uncertain cycles and optimization using dynamic programming is the main approach studied in this dissertation, for utilizing the specifics of wheel loader operation for optimal predictive control. 


\section{3}

\section{Wheel loader operation}

\subsection{Overview and the Short Loading Cycle}

The wheel loader is a versatile machine that comes in a wide variety of sizes, ranging from compact loaders at around 5 tonnes up to the heaviest machines at several hundred tonnes. The smaller machines are often a base tool used for a wide variety of tasks, such as handling of pallets, hay bales or other unit material, use as a snow plow or blower, or a carrier of various engineering tools such as hydraulic drills or brush cutters. The machines are however designed mainly for the purpose of bucket handling of bulk material, such as snow, soil, gravel, ore, wood chips or waste. For heavier loaders in particular, this is also the by far most common type of application, usually handling soil or granular minerals. Although bucket handling can involve dozing and moving of material, longer transports are less common due to the relatively low carrying capacity of these vehicles. The most common type of operation, and in particular the most common pattern of operation, is cyclic loading from a source to a nearby receiver, which is often next to the material source. Each cycle in this type of operation is denoted a 'short loading cycle'. This common cycle type forms the framework for the prediction in the optimal predictive controller, as defined in Section 2.4, that is the theme of this dissertation.

In the short loading cycle the loader moves material from a source to a nearby receiver. Figure 3.1 presents the general pattern of the cycle. Referring to the designations used in this figure, the cycle begins with the machine at the starting position at marker 4 . The machine moves forward and picks up a load at the source at position 1 , and reverses back to the starting position. Next the machine moves forward and leaves the load at the receiver at position 6 , and finally it reverses back to the starting position where the cycle ends. 


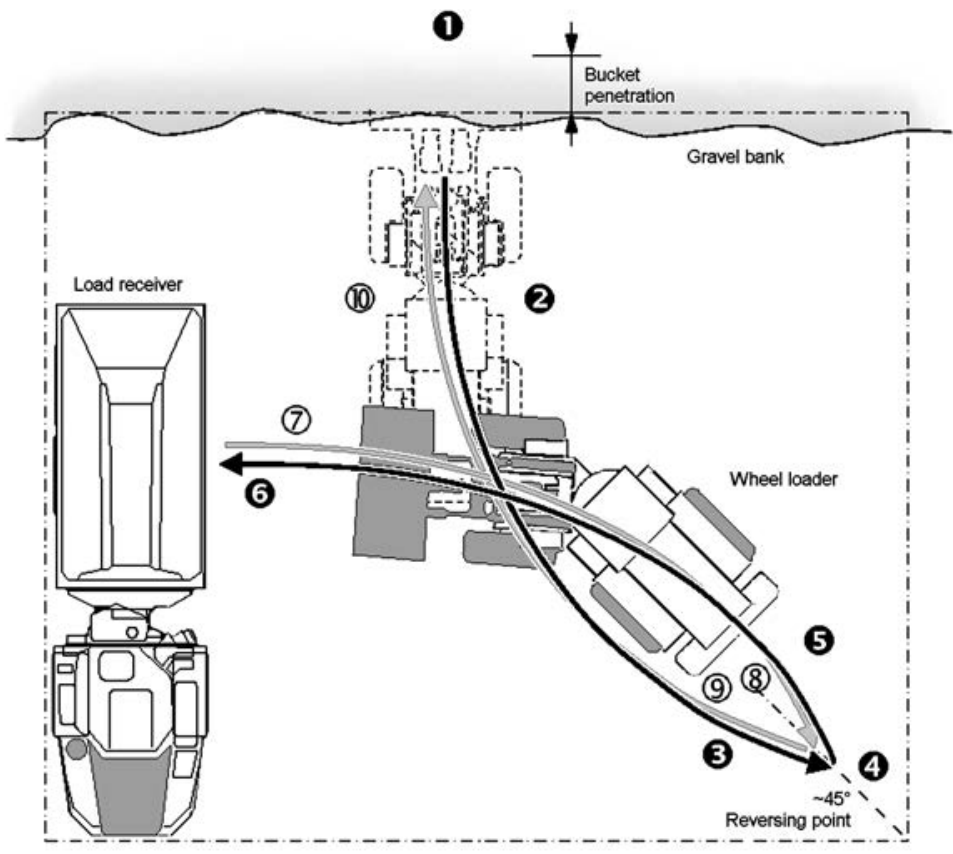

Figure 3.1: An overview of the short loading cycle, from [20].

The duration of, and distances in, the cycles vary with the type of material handled, the size of the machine and the experience of the driver, but for the loading cycle to be short, the two switches from backward to forward driving should be at roughly the same position and the machine should not travel a distance of more than about five times the circumference of the wheels in each leg of the cycle. A typical cycle for heavier loaders handling granular material can have a duration in the order of $5 s$ for each leg and an additional $5 s$ for filling the bucket at the source. The tool movement hydraulics, or bucket hydraulics, are separately controlled by the driver, but the pressure and required power trajectories generally follows a common pattern in the short loading cycle. During the bucket filling the bucket is usually both lifted and tilted while being pushed through the source pile. This produces high forces, both vertical and longitudinal, usually requiring very high powers both in the propulsion and the hydraulics. After the filling, the bucket is usually lifted more or less continuously during the second and third leg of the cycle, requiring significant power. The bucket emptying and the lowering of the same, during the fourth leg of the cycle, does in general not require significant power input. This cycle is repeated many times over, often with pauses or other operations between some of the cycles. The load receiver is often a dump truck or an articulated hauler, and the pauses occur when the truck has been filled and is replaced or emptied. The other operations that might occur primarily include operations for cleaning the working site from dropped material and preparing the source pile for faster 
loading when a load receiver becomes available.

The intention in this work is to utilize the characteristics of this operation for optimal predictive control. This requires a method for analyzing the operation, that first of all finds the patterns in the operation, and second enables a prediction that is useful for predictive control. Two potential prediction types were described in Section 2.4; pattern detection and repetition detection. The main difference is whether the operational patterns are pre-specified or not. The pattern detection concept is investigated in the appended paper 1, [73], and the repetition detection concept is described further in Section 3.2.

\subsection{Repetition detection}

The intention with analyzing the operation is to find a method for obtaining a prediction for some use in some suitable optimization method. The operation is often highly repetitive, as illustrated by the example in Figure 3.2. There is therefore a real possibility of producing a prediction from such repetition, if the repetition can be detected. The simplest method for detecting repetition might be to compare a piece of the recent history of a signal to the earlier history of the same signal, e.g. by the sum of the square of the difference. Tn the rest of this section the approach is explained and demonstrated through two examples.
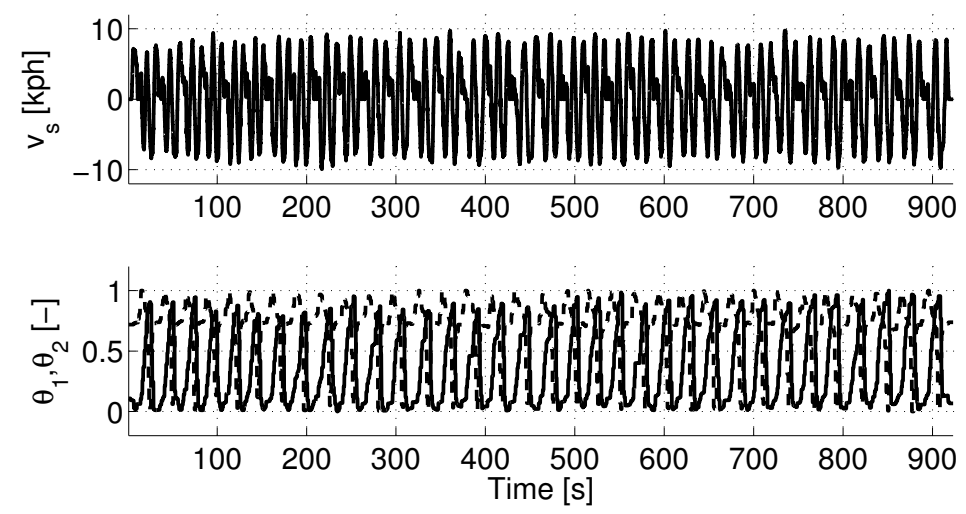

Figure 3.2: A set of data from wheel loader operation, represented by vehicle speed $v_{s}$, bucket lift angle $\theta_{1}$ (solid) and tilt angle $\theta_{2}$ (dashed). The set contains 34 short loading cycles and is an example of the highly repetitive operation.

Figure 3.3 shows a cutout of the bucket lift angle, $\theta_{1}$, data from Figure 3.2. In this example the process is at $590 \mathrm{~s}$, as marked with a vertical gray line, and a repetition detector is running. The detector picks the last fifteen seconds, as indicated by the darker line in the figure to the left, to use as a reference. This reference is then compared to the signal history. In the figure in the middle several such comparisons are made at about ten second intervals, and the best fit, which is at about $-27.5 \mathrm{~s}$, is indicated in black. In the figure to the right a 

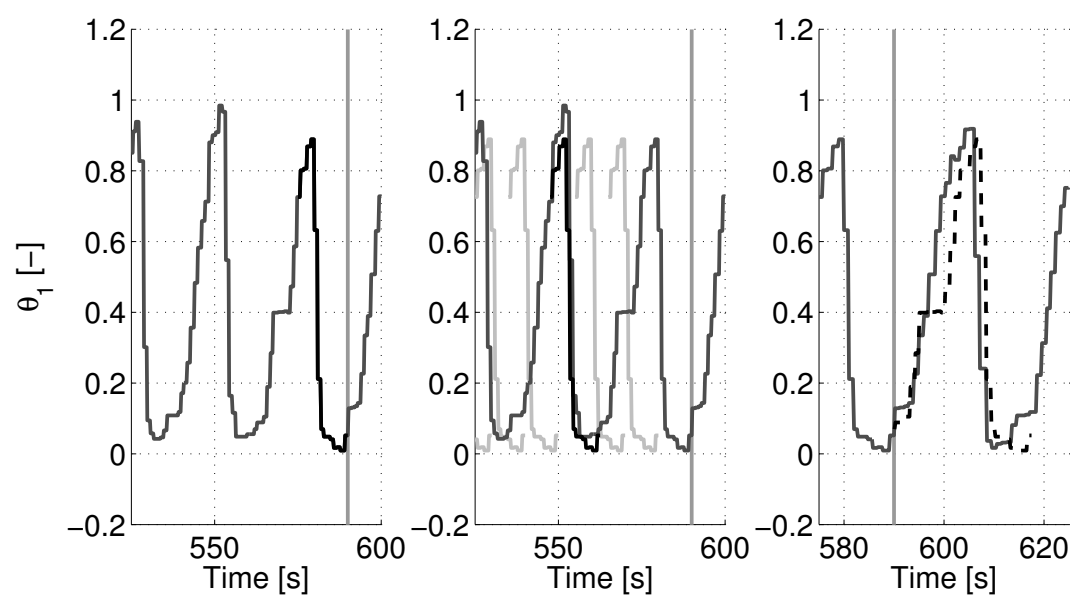

Figure 3.3: Comparison of the last $15 \mathrm{~s}$ of the signal $\theta_{1}$ to the earlier history of the signal, and a signal prediction based on the best fit, applied to data from the example in Figure 3.2.

prediction is constructed according to the dashed line, from the assumption that the operation is repeating with the detected $27.5 \mathrm{~s}$ period, by shifting the latest signal history $27.5 \mathrm{~s}$ into the future. Here the shifted signal is dashed and the actual signal is shown in gray. In this example the predicted signal trajectory agrees well to the actual trajectory. In the examples presented here, the fit in the comparisons are measured in the sum of the square of the difference between the two signals over the intervals, according to Equation (3.1).

$$
J=\sum_{i=0}^{H}\left(y_{k-i-\tau}-y_{k-i}\right)^{2}
$$

where $y$ is the signal scanned for repetition, $k$ is the instant of the scan, $\tau$ is the position in the signal history where the fit is evaluated, $H$ is the size of the signal window used in the comparison and $J$ is a measure of the fit. If $J$ is low only for some values of $\tau$ and these $\tau$-values are large enough, this indicates that the signal is repeating. Figure 3.4 shows the inverse of $J$ from the data in Figure 3.2, where dark indicates a good fit, along with the output from a simple detector which marks the first peak in $1 / J$ with a dashed gray line. In this example a time window of $15 \mathrm{~s}$ is used and the data is scanned $120 \mathrm{~s}$ back in time. The operation is highly repetitive and the time scales in the repeating cycle fits the size of the time window used in the detection, and therefore a clear, unambiguous and consistent detection of a repetition with $\sim 25 \mathrm{~s}$ cycle time is achieved, all without any predefined information. Another example of a highly repetitive set of data with longer cycle times is presented in Figure 3.5. In the later part of this second example, some longer cycles are driven. In these cycles there is a short transportation between each bucket filling and emptying. The same detector with the same parameters is applied to this data, and the result 
is presented in Figure 3.6. In this example correct and consistent detections are made in the first $1000 \mathrm{~s}$ of the data. In this part the detector quickly adopts to changes in the period caused by switches between different cycle types, which in this case are the short loading cycle and some working site preparation through a cleaning cycle. In the later part of the data the detector is however unable to pick out a period, even though the signal is clearly repetitive, as shown in Figure 3.5. The reason for the bad result in the later part is that the signal window used in the signal used in the comparison in general contains little information, especially during the transportation phases and thus the fit will almost always be good. Since there is not a distinct fit, a clear cycle time will not be found, as shown in Figure 3.6.

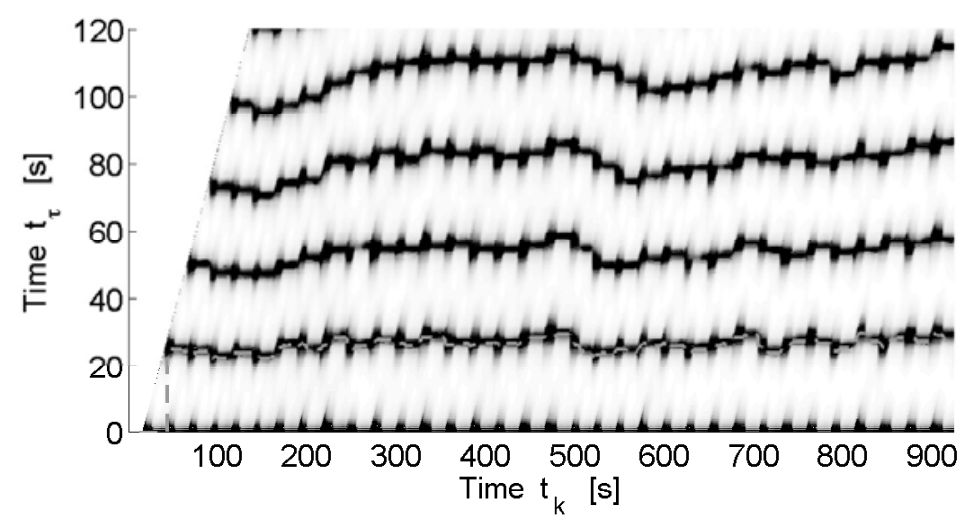

Figure 3.4: The output from a repetition detector applied to the data presented in Figure 3.2. Darker shade indicate similarity of historical data to recent data and the dashed line following the $\sim 25 \mathrm{~s}$ dark band indicates the first repetition.
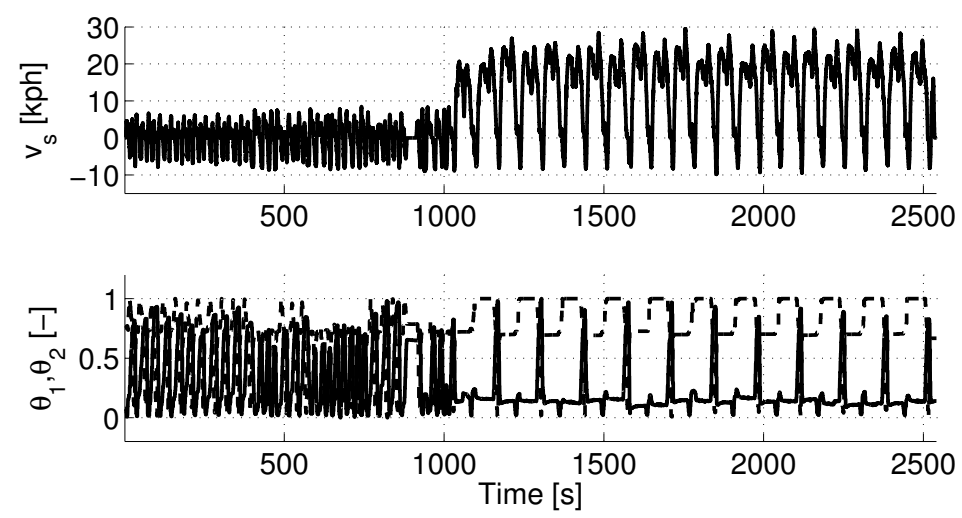

Figure 3.5: A set of data recorded in wheel loader operation. The set contains both short loading cycles, long loading cycles and some cleaning operation, and is an example of repetitive operation with longer time scales. 


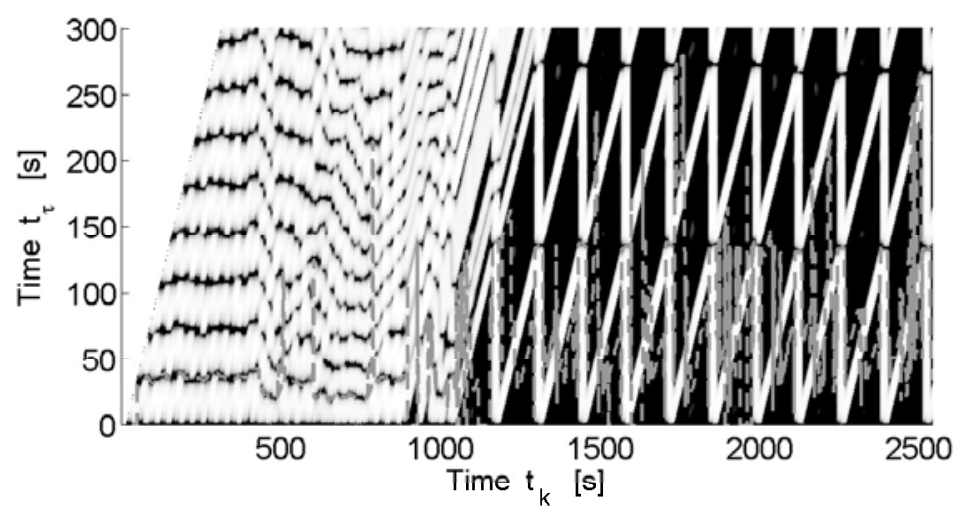

Figure 3.6: The output from a repetition detector applied to the data presented in Figure 3.5. Darker shade indicate similarity of historical data to recent data and the dashed line indicate the first repetition.

In the examples presented here a simple sum of squares fit is used, and only one signal is used in the fit calculation and repetition scan. Still, is some cases this very simple method produces a very clear and consistent detection of repetition. Figure 3.3 indicates that such a detection would also be useful for producing a prediction. The second example does however show that the simple least squares fit used here would not be sufficient for making predictions in all operating conditions. There are several more advanced methods for detecting repetition, such as those used in e.g. [1], [33], [60], [96] and [88], that could be expected to improve the detection. The positive results from the simple detector described here indicate that a practical repetition detector can be constructed. The implementation of such a detector would mean that a prediction would become available, although the accuracy of this would have to be thoroughly evaluated. The detector would be highly versatile since it could detect a wide range of driving cycles, with very little information specified beforehand. On the other hand, the resulting predictions would have uncertainties that would grow with the prediction horizon, and the prediction would only become available at the moment the detector finds a repetition. Any control optimization would therefore have to be performed online, and due to the relatively quick dynamics of the engine, especially in the engine speed, the optimization would have to be very fast. Any controller based on this type of prediction would also have to be able to handle changes in the repeating pattern. The combination of an uncertain prediction and a requirement for quick optimization pose a very difficult problem to solve, and this approach has therefore not been pursued further as part of the work presented in this dissertation. The approach followed is instead to, in advance, define one or a few operational patterns and perform control optimization against these patterns. The online controller then monitors the system for operation according to the predefined patterns, and when a detection is made, the controller can apply the corresponding control strategy. A framework for a cycle detector is presented in the appended paper 1, [73]. 


\section{References}

The "(Cited on $p . \mathbf{7 , 8 , 1 2 ) " ~ o f ~ t h e ~ r e f e r e n c e ~ l i s t ~ i n d i c a t e s ~ t h e ~ p a g e s ~ w i t h i n ~ t h e ~}$ introductory chapters of this compilation thesis, where the reference is used.

[1] M. Allmen and C.R. Dyer. Cyclic motion detection using spatiotemporal surfaces and curves. In Pattern Recognition, 1990. Proceedings., 10th International Conference on, volume 1, pages 365-370. IEEE, 1990. (Cited on p. 22)

[2] B.J. Alshaer, T.T. Darabseh, and M.A. Alhanouti. Path planning, modeling and simulation of an autonomous articulated heavy construction machine performing a loading cycle. Applied Mathematical Modelling, 37(7):5315-5325, 2013. (Cited on p. 15)

[3] J. Andersson, J. Åkesson, and M. Diehl. Casadi: A symbolic package for automatic differentiation and optimal control. In Recent Advances in Algorithmic Differentiation, pages 297-307. Springer, 2012. (Cited on p. 15)

[4] S. Atev, H. Arumugam, O. Masoud, R. Janardan, and N.P. Papanikolopoulos. A vision-based approach to collision prediction at traffic intersections. Intelligent Transportation Systems, IEEE Transactions on, 6(4):416-423, 2005. (Cited on $p$. 11)

[5] S. Behere, M. Törngren, and D-J. Chen. A reference architecture for cooperative driving. Journal of systems architecture, 59(10):1095-1112, 2013. (Cited on p. 11)

[6] R. Bellman. Dynamic Programming. Princeton University Press, 1957. (Cited on p. 13)

[7] A. Bemporad, M. Morari, and N.L. Ricker. Model predictive control toolbox. Matlab User's Guide, 1995. version 1. (Cited on p. 10)

[8] M. Bertozzi, A. Broggi, M. Cellario, A. Fascioli, P. Lombardi, and M. Porta. Artificial vision in road vehicles. Proceedings of the IEEE, 90(7):1258-1271, 2002. (Cited on p. 11)

[9] D.P. Bertsekas. Dynamic Programming and Optimal Control, volume 1. Athena Scientific, 3 edition, 2005. (Cited on p. 13)

[10] J.T. Betts. Survey of numerical methods for trajectory optimization. Journal of guidance, control, and dynamics, 21(2):193-207, 1998. (Cited on p. 14, 15)

[11] R. Bishop. A survey of intelligent vehicle applications worldwide. In Intelligent Vehicles Symposium, 2000. IV 2000. Proceedings of the IEEE, pages 25-30. IEEE, 2000. (Cited on p. 11)

[12] A. Bonchis, N. Hillier, J. Ryde, E. Duff, and C. Pradalier. Experiments in autonomous earth moving. In IFAC World Congress, pages 11588-11593. IFAC, 2011. (Cited on p. 15)

[13] M. Burke. Powertrain efficiency optimization of the torotrak infinitely variable transmission 
(ivt). In Transmission \& Driveline Systems Symposium, number 2003-01-0971. SAE, 2003. (Cited on p. 5)

[14] E.F. Camacho and C. Bordons. Model predictive control. Springer, 2 edition, 2013. (Cited on p. 10)

[15] M. Diehl. Script on numerical optimal control by m.diehl. http://homes.esat.kuleuven.be/ mdiehl/TRENTO/numopticon.pdf, 2011. (Cited on p. 14)

[16] A. Emadi, K. Rajashekara, S.S. Williamson, and S.M. Lukic. Topological overview of hybrid electric and fuel cell vehicular power system architectures and configurations. Vehicular Technology, IEEE Transactions on, 54(3):763-770, 2005. (Cited on p. 5)

[17] E. Faggioli, P. Rena, V. Danel, X. Andrieu, R. Mallant, and H. Kahlen. Supercapacitors for the energy management of electric vehicles. Journal of Power Sources, 84(2):261-269, 1999. (Cited on $p .5$ )

[18] R. Filla. Alternative systems solutions for wheel loaders and other construction equipment. In 1st International CTI Forum Alternative and Hybrid Drive Trains. CTI, 2008. (Cited on $p$. 4)

[19] R. Filla. Quantifying Operability of Working Machines. dissertation, Linköping University, 2011. (Cited on p. 6)

[20] R. Filla. Study of a method for assessing operability of working machines in physical and virtual testing. International Journal of Vehicle Systems Modelling and Testing, 7(3):209234, 2011. (Cited on p. 18)

[21] T. Gandhi and M.M. Trivedi. Pedestrian collision avoidance systems: A survey of computer vision based recent studies. In Intelligent Transportation Systems Conference, 2006. ITSC'O6. IEEE, pages 976-981. IEEE, 2006. (Cited on p. 11)

[22] C.E. Garcia, D.M. Prett, and M. Morari. Model predictive control: theory and practice-a survey. Automatica, 25(3):335-348, 1989. (Cited on p. 10)

[23] R. Ghabcheloo, M. Hyvönen, J. Uusisalo, O. Karhu, J. Jara, and K. Huhtala. Autonomous motion control of a wheel loader. In Proceedings of the ASME 2009 Dynamic Systems and Control Conference, pages 1339-1346. ASME, 2009. (Cited on p. 15)

[24] D. Gillespie. Markov Processes; An Introduction for Physical Scientists. Academic Press, 1991. (Cited on p. 12)

[25] Robert Bosch GmbH. Bosch Automotive Handbook. John Wiley \& Sons Ltd., 7 edition, 2007. (Cited on p. 3, 4)

[26] C. Guardiola, B. Pla, D. Blanco-Rodriguez, and A. Reig. Modelling driving behaviour and its impact on the energy management problem in hybrid electric vehicles. International Journal of Computer Mathematics, 91(1):147-156, 2014. (Cited on p. 6)

[27] L. Guzzella and A. Sciarretta. Vehicle Propulsion Systems. Springer Verlag, 2 edition, 2007. (Cited on p. 3)

[28] M.J. Hapeman, J. Long, and D.L. Plette. Diesel electric locomotive propulsion systems-a look into the future. Industry Applications, IEEE Transactions on, (3):495-501, 1986. (Cited on p. 5)

[29] E. Hellström. Look-ahead Control of Heavy Vehicles. dissertation, Linköping University, 2010. (Cited on p. 6, 11, 13)

[30] L.O. Hewko and T.R. Weber. Hydraulic energy storage based hybrid propulsion system for a terrestrial vehicle. In Energy Conversion Engineering Conference, 1990. IECEC-90. Proceedings of the 25th Intersociety, volume 4, pages 99-105. IEEE, 1990. (Cited on p. 5)

[31] D.W. Hinde and M. Hinde. Electric and diesel-electric locomotives. Macmillan, 1948. (Cited on p. 5)

[32] B. Holger, J. Emmert, and K. Dietmayer. Continuous driver intention recognition with hidden markov models. In Intelligent Transportation Systems, 2008. ITSC 2008. 11th International IEEE Conference on, pages 1189-1194. IEEE, 2008. (Cited on p. 12)

[33] J-L. Hsu, C-C. Liu, and A.LP. Chen. Discovering nontrivial repeating patterns in music data. Multimedia, IEEE Transactions on, 3(3):311-325, 2001. (Cited on p. 22)

[34] S. Jeon, S. Jo, Y. Park, and J. Lee. Multi-mode driving control of a parallel hybrid electric vehicle using driving pattern recognition. Journal of dynamic systems, measurement, and control, 124(1):141-149, 2002. (Cited on p. 12)

[35] L. Johannesson, M. Åsbogård, and B. Egardt. Assessing the potential of predictive control 
for hybrid vehicle powertrains using stochastic dynamic programming. IEEE Transactions on Intelligent Transportation Systems, 8(1):71-83, 2007. (Cited on p. 6, 12, 13)

[36] H. Khayyam, S. Nahavandi, and S. Davis. Adaptive cruise control look-ahead system for energy management of vehicles. Expert Systems with Applications, 39(3):3874-3885, 2012. (Cited on p. 6)

[37] A.J. Kotwicki. Dynamic models for torque converter equipped vehicles. In SAE technical papers, number 820393. SAE, 1982. (Cited on p. 3)

[38] J. Krumm. A markov model for driver turn prediction. In SAE technical papers, number 2008-01-0195. SAE, 2008. (Cited on p. 12)

[39] T. Leroy, F. Vidal-Naquet, and P. Tona. Stochastic dynamic programming based energy management of hev's: an experimental validation. In IFAC World Congress, pages 48134818. IFAC, 2014. (Cited on p. 6, 12, 13)

[40] L. Li and F. Wang. Cooperative driving at blind crossings using intervehicle communication. Vehicular Technology, IEEE Transactions on, 55(6):1712-1724, 2006. (Cited on p. 11)

[41] C. Lin, S. Jeon, H. Peng, and J. Moo. Driving pattern recognition for control of hybrid electric trucks. Vehicle System Dynamics: International Journal of Vehicle Mechanics and Mobility, 42(1-2):41-58, 2004. (Cited on p. 12)

[42] C. Lin, H. Peng, and J.W. Grizzle. A stochastic control strategy for hybrid electric vehicles. In American Control Conference, 2004. Proceedings of the 2004, volume 5, pages 4710-4715. IEEE, 2004. (Cited on p. 12)

[43] J. Liouville. Note sur la théorie de la variation des constantes arbitraires. Journal de Mathématiques Pures et Appliquées, 3:342-349, 1838. (Cited on p. 14)

[44] S. Liu and B. Paden. A survey of today's cvt controls. In Proceedings of the 36th Conference on Decision and Control, pages 4738-4743. IEEE, 1997. (Cited on p. 5)

[45] S.E. Lyshevski. Energy conversion and optimal energy management in diesel-electric drivetrains of hybrid-electric vehicles. Energy conversion and management, 41(1):13-24, 2000. (Cited on p. 5)

[46] G. Maggetto and J. Van Mierlo. Electric vehicles, hybrid electric vehicles and fuel cell electric vehicles: state of the art and perspectives. In Annales de Chimie Science des Materiaux, volume 26, pages 9-26. Elsevier, 2001. (Cited on p. 5)

[47] M. Magnusson and H. Almqvist. Consistent pile-shape quantification for autonomous wheel loaders. In 2011 IEEE/RSJ International Conference on Intelligent Robots and Systems, pages 4078-4083. IEEE, 2011. (Cited on p. 15)

[48] L. Mangialardi and G. Mantriota. Power flows and efficiency in infinitely variable transmissions. Mechanism and machine theory, 34(7):973-994, 1999. (Cited on p. 4)

[49] J-P. Marec. Optimal space trajectories, volume 1. Elsevier Scientific Publishing Company, 1979. (Cited on p. 14)

[50] P. Mattsson and M. Åkerblom. Continuously variable transmission and a working maching including a continuously variable transmission. Patent, 2012. WO 2012/008884 A1. (Cited on $p$. 8)

[51] Caterpillar. Products: Wheel loaders, 2014. http://www.cat.com/en_US/products/new/ equipment/wheel-loaders.html. (Cited on p. 3)

[52] Hyundai Heavy Industries. Products: Wheel loaders, 2014. http://constructionequipment. hyundai.eu/en/products/wheeled-loaders-loaders. (Cited on $p .3$ )

[53] Kawasaki Construction Machinery. Products: Wheel loaders, 2014. http://www. kawasakiloaders.com/products/zv-2.aspx. (Cited on p. 3)

[54] Komatsu. Products: Wheel loaders, 2014. http://www.komatsuamerica.com/equipment/ wheelloaders. (Cited on p. 3)

[55] LiuGong. Products: Wheel loaders, 2014. http://www.liugong.com/en_me/products/loader.htm. (Cited on $p$. 3)

[56] Volvo Construction Equipment. Products: Wheel loaders, 2014. http://www.volvoce.com/ constructionequipment/na/en-us/products/wheelloaders/wheelloaders/Pages/introduction . aspx. (Cited on p. 3)

[57] K. McDonough, I. Kolmanovsky, D. Filev, D. Yanakiev, S. Szwabowski, and J. Michelini. Stochastic dynamic programming control policies for fuel efficient in-traffic driving. In American Control Conference (ACC), 2012, pages 3986-3991. IEEE, 2012. (Cited on p. 12, 13) 
[58] D. Mitrovic. Reliable method for driving events recognition. IEEE Transactions on Intelligent Transportation Systems, 6:198-205, 2005. (Cited on p. 12)

[59] S.J. Moura, H.K. Fathy, D.S. Callaway, and J.L. Stein. A stochastic optimal control approach for power management in plug-in hybrid electric vehicles. Control Systems Technology, IEEE Transactions on, 19(3):545-555, 2011. (Cited on p. 12)

[60] K.B. Murray, D. Gorse, and J.M. Thornton. Wavelet transforms for the characterization and detection of repeating motifs. Journal of molecular biology, 316(2):341-363, 2002. (Cited on p. 22)

[61] Y. Nambu. Generalized hamiltonian dynamics. Physical Review D, 7(8):2405, 1973. (Cited on $p$. 14)

[62] V. Nezhadali and L. Eriksson. Modeling and optimal control of a wheel loader in the lifttransport section of the short loading cycle. In 7th IFAC Symposium on Advances in Automotive Control, pages 195-200. IFAC, 2013. (Cited on p. 3)

[63] T. Nilsson. Optimal engine operation in a multi-mode CVT wheel loader. Technical report, Linköping University, 2012. LiU-TEK-LIC-2012:32, Thesis No. 1547. (Cited on p. 7)

[64] T. Nilsson, A. Fröberg, and J. Åslund. Optimized engine transients. In 7th IEEE Vehicle Power and Propulsion Conference, pages 1-6. IEEE, 2011. (Cited on p. 7)

[65] T. Nilsson, A. Fröberg, and J. Åslund. Fuel potential and prediction sensitivity of a power-split cvt in a wheel loader. In IFAC Workshop on Engine and Powertrain Control, Simulation and Modeling, pages 49-56. IFAC, 2012. (Cited on p. $7, \boldsymbol{8}$ )

[66] T. Nilsson, A. Fröberg, and J. Åslund. On the use of stochastic dynamic programming for evaluating a power-split cvt in a wheel loader. In 8th IEEE Vehicle Power and Propulsion Conference, pages 840-845. IEEE, 2012. (Cited on p. $7, \boldsymbol{8}$ )

[67] T. Nilsson, A. Fröberg, and J. Åslund. Optimal operation of a turbocharged diesel engine during transients. SAE International Journal of Engines, 5(2):571-578, 2012. (Cited on p. 5, 7)

[68] T. Nilsson, A. Fröberg, and J. Åslund. Fuel and time minimization in a cvt wheel loader application. In 7th IFAC Symposium on Advances in Automotive Control. IFAC, 2013. (Cited on p. $\mathbf{7 ,} \boldsymbol{8}$ )

[69] T. Nilsson, A. Fröberg, and J. Åslund. Development of look-ahead controller concepts for a wheel loader application. Oil $\&$ Gas Science and Technology - Rev. IFP, 2014. (Cited on p. $3,6,7,8)$

[70] T. Nilsson, A. Fröberg, and J. Åslund. Minimizing fuel use during power transients for naturally aspirated and turbo charged diesel engines. Technical Report LiTH-R-3077, Department of Electrical Engineering, Linköpings Universitet, SE-581 83 Linköping, Sweden, 2014. (Cited on $p .6, \boldsymbol{7})$

[71] T. Nilsson, A. Fröberg, and J. Åslund. Using stochastic dynamic programming for look-ahead control of a wheel loader diesel electric transmission. In IFAC World Congress, pages 66306635. IFAC, 2014. (Cited on p. 7, 8)

[72] T. Nilsson, A. Fröberg, and J. Åslund. Predictive control of a diesel electric wheel loader powertrain. Control Engineering Practice, Submitted. (Cited on p. 6, 7, 8)

[73] T. Nilsson, C. Sundström, P. Nyberg, E. Frisk, and M. Krysander. Robust driving pattern detection and identification with a wheel loader application. International Journal of Vehicle Systems Modelling and Testing, 9(1):56-76, 2014. (Cited on p. 6, 7, 19, 22)

[74] E. Ohn-Bar, A. Tawari, S. Martin, and M.M. Trivedi. Predicting driver maneuvers by learning holistic features. In Intelligent Vehicles Symposium Proceedings, pages 719-724. IEEE, 2014. (Cited on p. 12)

[75] G. Paganelli, T.M. Guerra, S. Delprat, J. Santin, M. Delhom, and E. Combes. Simulation and assessment of power control strategies for a parallel hybrid car. Proceedings of the Institution of Mechanical Engineers, part D: Journal of Automobile Engineering, 214:705-717, 2000. (Cited on p. 14)

[76] R. Pfiffner. Optimal Operation of CVT-Based Powertrains. dissertation, ETH, Zurich, 2001. (Cited on p. $\boldsymbol{5}, \boldsymbol{6}$ )

[77] J. Ploeg, A. Serrarens, and G.J. Heijenk. Connect \& drive: design and evaluation of cooperative adaptive cruise control for congestion reduction. Journal of Modern Transportation, 19(3):207-213, 2011. (Cited on p. 11)

[78] L.S. Pontryagin, V.G. Boltyanskii, R.V. Gamkrelidze, and E.F. Mishchenko. The Mathemat- 
ical Theory of Optimal Processes. Interscience Publishers, 1962. (Cited on p. 14)

[79] S.J. Qin and T.A. Badgwell. A survey of industrial model predictive control technology. Control engineering practice, 11(7):733-764, 2003. (Cited on p. 10)

[80] D. Revuz. Markov Chains. Elsevier Science Publishers, 1975. (Cited on p. 12)

[81] G. Ripaccioli, D. Bernardini, S. Di Cairano, A. Bemporad, and I. Kolmanovsky. A stochastic model predictive control approach for series hybrid electric vehicle power management. In American Control Conference (ACC), 2010, pages 5844-5849. IEEE, 2010. (Cited on p. 12)

[82] H. Salmane, Y. Ruichek, and L. Khoudour. Using hidden markov model and dempster-shafer theory for evaluating and detecting dangerous situations in level crossing environments. In Advances in Artificial Intelligence, pages 131-145. Springer, 2013. (Cited on p. 12)

[83] A. Sathyanarayana, P. Boyraz, and J. Hansen. Driver behavior analysis and route recognition by hidden markov models. In Vehicular Electronics and Safety, 2008. ICVES 2008. IEEE International Conference on, pages 276-281. IEEE, 2008. (Cited on p. 12)

[84] A. Sciarretta and L. Guzzella. Control of hybrid electric vehicles. Control Systems, IEEE, 27:60-70, 2007. (Cited on p. 14)

[85] S. Shen and F.E. Veldpaus. Analysis and control of a flywheel hybrid vehicular powertrain. IEEE Transactions on Control Systems Technology, 5:645-660, 2004. (Cited on p. 5)

[86] M. Sivertsson and L. Eriksson. Time and fuel optimal power response of a diesel-electric powertrain. In IFAC Workshop on Engine and Powertrain Control, Simulation and Modeling, pages 262-269. IFAC, 2012. (Cited on p. 5)

[87] M. Sivertsson and L. Eriksson. Optimal transient control trajectories in diesel-electric systemspart 1: Modeling, problem formulation and engine properties. Journal of Engineering for Gas Turbines and Power, 137(2), 2015. (Cited on p. 6)

[88] E. Soei, C. Bellebaum, and I. Daum. Relational and non-relational memoryelectrophysiological correlates of novelty detection, repetition detection and subsequent memory. European Journal of Neuroscience, 29(2):388-398, 2009. (Cited on p. 22)

[89] N. Srinivasa. Vision-based vehicle detection and tracking method for forward collision warning in automobiles. In Intelligent Vehicle Symposium, 2002. IEEE, volume 2, pages 626-631. IEEE, 2002. (Cited on p. 11)

[90] N. Srivastava and I. Haque. A review on belt and chain continuously variable transmissions (cvt): dynamics and control. Mechanism and Machine Theory, 44:19-41, 2009. (Cited on p. 5)

[91] J. Stecki and P. Matheson. Advances in automotive hydraulic hybrid drives. In Proceedings of the 6th JFPS International Symposium on Fluid Power, pages 664-669. JFPS, 2005. (Cited on $p$. 5)

[92] G. Stein, A. Fröberg, J. Martinsson, B. Brattberg, R. Filla, and J. Unnebäck. Fuel efficiency in construction equipment - optimize the machine as one system. In 7th AVL International Commercial Powertrain Conference. AVL \& SAE, 2013. (Cited on p. 8)

[93] R.F. Stengel. Optimal control and estimation. Courier Dover Publications, 2012. (Cited on p. 15)

[94] O. von Stryk and R. Bulirsch. Direct and indirect methods for trajectory optimization. Annals of operations research, 37(1):357-373, 1992. (Cited on p. 14, 15)

[95] J. Wang, W. Xu, and Y. Gong. Real-time driving danger-level prediction. Engineering Applications of Artificial Intelligence, 23(8):1247-1254, 2010. (Cited on p. 12)

[96] L. Wang, E.S. Chng, and H. Li. Efficient sparse self-similarity matrix construction for repeating sequence detection. In Multimedia and Expo, 2009. ICME 2009. IEEE International Conference on, pages 458-461. IEEE, 2009. (Cited on p. 22)

[97] C.O. Weisenbach. Hydrostatic transmission applications. In 19th Annual Earthmoving Industry Conference, number 680259. SAE, 1968. (Cited on p. 5)

[98] J. Wenger. Automotive radar-status and perspectives. In Compound Semiconductor Integrated Circuit Symposium, 2005. CSIC'05. IEEE, pages 4-pp. IEEE, 2005. (Cited on p. 11) 

Papers 



\section{Papers}

The articles associated with this thesis have been removed for copyright reasons. For more details about these see:

http://urn.kb.se/resolve?urn=urn:nbn:se:liu:diva-112722 